\title{
Semantic Nature of ICT (Information and Communication Technology)
}

\author{
Malak Mammadova ${ }^{1}$ \\ ${ }^{1}$ Azerbaijan University of Languages, Baku, Azerbaijan \\ Correpondence: Malak Mammadova, Azerbiajan University of Languages, Baku, Azerbaijan. E-mail: \\ malakmammadova@box.az
}

Received: May 26, 2015 Accepted: July 10, 2015 Online Published: July 30, 2015

doi:10.5539/ijel.v5n4p149 URL: http://dx.doi.org/10.5539/ijel.v5n4p149

\begin{abstract}
In the article self-belonging features of terminological lexics in the language system are analysed and semantic nature (essence) of ITC terms in all language levels (phonetic, lexic, morphological, syntactic levels) is investigated.
\end{abstract}

Keywords: terminology, semantics, lexical, syntactic peculiarities, correlation

\section{Introduction}

Terminological semantics is considered a problem more linked with the contents of concept of term. Concept is a thought, reflecting the objects and events of reality in the generalized form, with the help of their coorelations and peculiarities: peculiarities and coorelations in the concept, act as general and specific features, linked with object and event classes (Yarcheva, 1990).

In any field of science terms in the process of oral and written intercourse, express the notions related the same field. Namely, specialists of this or that field use special professional lexics or terms during the intercourse.

This makes it possible for them to express their thought more exactly and correctly.

\section{Scope of the study}

Depending upon the condition of intercourse, any language sign may express either an object or conception on an object. Putting in other words, a language sign can be actualized both as a "word-object" or as a "word-concept". Nevertheless, only by addressing to the contents we can determine the borderline between the "naming of an object" and the "expression of a concept".

Any term of ICT can be called as both, an object class (or a certain object) and a special concept depending upon the concrete condition of intercourse. For example: configurator concentrator, response, bootstrapping etc. While in the expression bootstrapping the concept correlation of the term is actualized, but in the term configurator object correlation is actualized.

As B.N. Golovin and R.Y. Kobrin noted, in the first plant in the term, its link with the concept is mentioned, but its relation to the real object remains in the shade (Golovin \& Kobrin, 1987) Description of the meaning of the terms in the terminological practice, is carried out paralelly with the composition of the explanation of the concepts which they express: the meaning of word-term consists of the total sum of elementary semantic units, but these units are the two signs depending on each-other at a certain degree, they do not enjoy the same rights, one of which is the sign of the closest type, but the other is the sign of type distinction (concept of dependence).

The expression of "scientific-technical term" can be determined as a nominative group (word combination consisting of a noun or substantive) related to a certain scientific-technical concept, belonging to a certain collection of texts, expressing the constant complextion of signs of the concept (Marusenko, 1981). From this determination we may come to the conclusion that term as any word or word combination possesses the feature of nominativity.

There exist some other view-points on the inner nature of term. The supporters of substantial thought consider that terms having monosemantic feature as to the contents, but from the view of expression, being characterized by the serious grammatical structure of a language, are special signs of types of mathematical symbols. In reality 
it is not like this. First of all, we must say that in terminology policemy being more observed, secondly there being no seriously organized grammar language structures, they are as well as they are in the literary language.

As to the functional view, put forth in the works of G.O. Vinokur, as a distinctive feature of a term, acception of expression function of the special professional concept is characteristic.

Information on the generalization of a certain side and features, groups, classes being homogenous, in the first plan with logical distribution in the term helps to specify the meaning of the term, it increases the degree of certainly and at the same time it makes it unfit for setting up narratives to express "literary meaning".

In comparison with commonly-used word while learning the semantic structure of a term B.N. Golovin numerates some semantic features of word-term: the meaning of word-term associates it first of all not with the class of objects, their types, with professional scientific technical concept, with a certain professional activity and that's why it requires to be understood in the frame of this field of profession; in such situations word-term can rise to the highest level of departing from the reality, even it can be isolated with it; the meaning of word-term gives possibility of creating individual concepts, peculiar for the investigation of some scientists.

Despite the fact that they possess the expressiveness of phrasiologisms and a number of features peculiar to them, from the semantic view-point, term-phrasemes remind us of phrase of logical combinations. Any feature uniting the phrase of logical combination and compound term shows that behind them exist fixed concept and structure, established in a standard form.

In direct connection with the problem of lexic meaning of a term stands the problem of motivation, based on the principle of nomination, being more general. Under the concept of motivation usually such an event is understood, in which "the given contents at a more or less degree should became similar", in other words, the transparency of inner form of a word should appear (Kandelaki, 1977).

Names, introduced in the language became substantiated (motivized) or unsubstantiated (ummonitivized) to embrace some elements of reality. The difference between them lies in the fact that the substantiated name, which we observe for the first time, while giving us possibility to surmise what it expresses, unsubstantiated name can in no way help us in this problem. The reason what it is connected with, can be easily understood. While we can divide the substantiated name with the help of other words closer in meaning to it, into two parts, each part of which possesses a real meaning, in the unsubstantiated names this can't be done (Matezius, 2003).

Traditionally, the following types of terminological units are mentioned: word-forming-morphological, syntactic and semantic types. V.P. Danilenko considers that terms having been as formed by means of suffixes, term-word combinations can be considered substantiated (Danilenko, 1977). This thought finds its affirmation in ICT terms as well. For ex: a term formed by means of suffixes as overloading; a term-compound word backslash; a word having become a term as a result of semantic transference of meaning as handler-etc.

In the ICT terminology we also come across unsubstantiated (having the form of a sign) terms. Their naming motivation is unknown for us. They belong to them simple derivations, terms-calka, borrowed words, terms derived from special names borrowed by metonymic transference of meaning for ex: machine translation (a term-calka, copied from french): station (the point of entrance and exit of system of distribution of the procession of the given materials).

This term, first being in latin (stationêm, nom. statio) has been borrowed from French (station); baud (the unit of speed of sending information) is associated with the name of French engineer M.E.Baudot.

At terminology study, there exist other view points associated with motivation problem of the term. I.S. Toroptsov investigated three methods (three methods of motivation) linked with sound coverage of the meaning:1) sign substantiation 2) contents substantiation, 3) imitation substantiation (Toropchov, 1964). He indicated 5 features in word forming lexic objectivization. They bear the preparation stages and are called "stages of lexic" objectivization. The first stage is substatiations and the second is coordination. He indicates two principles which condition the substantiation as concrete substantiation and abstract classification (Toropchov, 1964).

T.Z.Kandelaki indicates some changes which he makes to the scheme of stages of lexic objectivization:while choosing a model for the creation of a term, with the help of closest type concept, necessary part of speech (and with the help of some other features) is determined and within this part of speech, while determining the list of adequate lexic-semantic group, the choice of part of name and the choice of the most adequate suffix takes place. Just as to this reason, essentially here not only two stages, but also more (three or four) stages exist (Kandelaki, 1977). 
As we deal with term and its semantic nature, the results of investigation find their reflections in compiling the vocabulary explanation. Semantis is the whole contents of information, expressed by a language or by any unit (word, grammatical form of a word, word combination, a sentence) of a language they express a system which is not determined.

The field which semantics directly studies is a policemantic word (for example, a noun, verb, adverb, adjective) and which is established by the principle of a "semantic triangle". It is systematization of sound and graphics associated with imagination and concept on the object, which is called intentional object, meaning, significant on the one hand, and on the other hand it is systematization of a foreign element of the object of reality (an object, an event, a process, a feature) which are called denotats, referent in the semantic theory determined by the conscious and language system (Yarcheva, 1990).

The determination of semantics which we have mentioned above refers to a natural language but as we know on the basis of natural languages, artificial languages are formed as well. An example to this we can show algorythm languages programmed by ICT. The language of informatics studies a language as a means of usage of information and its sending. As a natural language informatics acts in the deeper phonological structure, in the lexis and semantic level and in all the levels its semantics is studied.

\section{Computer Phonosemantics}

In the vocabulary explanation the determination of semantics is like this: Semantics is a scientific subject learning all the general acting notions and structure of different signs (semantic) which keeps information and sends it (Yarcheva, 1990).

Specialized artificial languages in the system of signs, especially the language of human being machine intercourse (algorithmic and programmed languages, the language of operating system belong to the system signs). It is known to all that the commonest objective law of semiotics is isomorphism-the similarity of structure of form of contents and expression, and as a result of this isomorphism is at a certain degree, similarity between expression and contents.

Above the explanation of phonosemantics is given, but no word is said on the name of the term, it is only dealt with the systematization of informational quantum, fitting to semantic systems and systematization of signs. "The power of voice is adequate with the power of emotion or the urgency of the contents: Sound (I) in different languages is adequate to the meaning of lessening and caressing, but bemol sounds ( $u$, i type sounds) different from the one which, we have mentioned (as to the comparison with each-other but as to the principles of confrontation) express the meaning of enlarging of the meaning of malice, hate ------ . The prolongation of the vowel of the root of the word may express the meaning of the length of the action, but the repeatition of the root may express the repeatition of the action" (Yarcheva, 1990).

We think that in the essence of the book of G.Osqud "The demention of Meaning" on which A.P. Juravlyov has written stands just this analogical principle. His book deals with G. Osgud's semantic cube, three dimensioned locality, more exactly saying, areal semantics locality with high quality. Locality with three dimensions has been created by three scales: "yaxşı" (good) - “ pis” (bad), "güclü” (strong) - "zəif” (weak), “ hərəkətli” (movable) "sabit" (constant). The author thinks that three factors stand on which, we cognize the world: 1) "yaxş1-pis" (good-bad), "xeyirli-ziyanlı" (useful, damageful) the evatuation factor which contains scale features: 2) "hərəkətli-sabit" (movable-constant), "cəld-yavaş (quick-slow), "aktiv-passiv" (active-passive) and so on, which contains the factor of activeness (Juravlyov, 1987). Work in this direction goes on: high quality classificator forming the world groups, which is able to cognize them, has been prepared. Kibernetics is always seeking out the ways of understanding the meaning. "Voicing, different from the contents, is the form of language units which is expressed substantially, which can be felt, can be measured, which is more easily understood by Kibernetics. If a form is contents, and a language establishes a part of the contents, this is just a way, leading you to cognize the contents that you look for. (9) So, for the sake of carrying out the correct modeling of computer of phonosemantics of Kibernetics, they use their own means in measuring the voice contents, especially "semantic differential" and other means.

Lexic semantics. "Lexic in the Greese language, is the vocabulary of a language" (Yarcheva, 1990). This term in the separately taken layers of the language, for example in terminology, especially in ICT terminology too, is widely used.

In the linguistic terminology, the term lexicon is used in two meanings: 1) the same of the dictionary word: 2) lexics (vocabulary, for example a special dictionary, terminological (6). In the terminology of ITC too, the word "lexicon" has two meanings: 1) collection of words used by any person, 2) the name of the editor working for 
PEHM in the field of MS-DOS, for example, programming lexicon, terminology used by the programists. In linguistics and informatics there exists just the same term which is exactly used in the Azerbaijani language: In linguistics "lexeme" is a word which is studied together with concrete grammatical forms and with flexions, which it expresses, including the possible concrete meaning variants together with the unit of the dictionary. In informatics lexeme, as to the agreement is the language constructions, being the electron bearer of the contents; it is the minimal unit expressing the language meaning (Pershikov \& Savinkov, 1991).

While learning morpheme of lexics comparatively together with the semantics of derivation having the same roots (linguistics-informatics) we may come to the conclusion that these terms as semantic elements posses general importance. This is not occasional that as it is above-mentioned, artificial languages have been formed on the basis of natural languages and have developed, though for the lexics of terminological units the asymmetry of language signs is characteristics, as it is in many other languages lexis semantics of ITC terminology differs from the lexis units of general literary language and from the semantics of linguistic terms. In different science semantics of terminology reflects only the notions characteristic to a certain science.

The semantic identity of the determination of the concept named by a concrete term for terminology is characteristic. In terminological lexic one type of lexis meaning is advantageous, namely, the object which is expressed and expresses and which fits to the nature of terminology is directly a nominative type, fitting to the principle of logical coordination. Even in the scientific language the term fraseologisms which are lexicalized carry out the nominative function of names (Danilenko, 1977).

\section{Syntactic Semantics}

Any language of human-machine intercourse sets up semiotic system. There exist three types of semiotic divisions (level, aspect) — syntactic, semantic and programmatic divisions.

As to the syntactic level in the chain of speech and generally in the time systematization as a link between the signs, semantic level generally as the bearer of sign, as the link between the object and the concept about the object is determined, but as the programmatic signs, the link between their users is determined (Marusenko, 1981). In the computer-human dialogue these ties are easily observed.

In the "explanatory dictionary on Informatics" (Pershikov \& Savinkov, 1991) the following types of syntax are mentioned: outer syntax: the language of the syntax of programming reflecting its features, the produced ones, not depending on the given ones: deeper syntax: the total sum of rules of description of programmers and mathematical constructions being survey; two-measured syntax (not being linex): the total sum of rules of formation of language constructions in the form of time-table (different from the syntax, constructions of which are written in one line): widening syntax: syntax giving possibility to the widening (enlarging) of formation of new rules of language constructions. The basis of the numerated types of determinations lies in the formation of rules of artificial language constructions.

These rules intend language constructions and links between the syntagms. "Syntagm is a group of lexic units linked with semantic ties; in the language of information-search, it is a sentence" (Pershikov \& Savinkov, 1991) Explaining the meaning of syntactic semantics, A.P. Juravlyov writes: "The main issues in the structure and construction of the sentence are not the elements establishing the sentence, but are the links among these elements. That's why the meaningfulness of a syntactic form (as it is in phonosemantics) is not the meaningfulness of the elements, but that is the coordination among the elements of syntactic constructions. Without the participation of other elements of the sentence (words, sounds) these ties themselves, specially relying upon the main concept and expressive contents of the sentence and the whole text, as if describe the ties among the human beings and symbolize them" (Juravlev, 1987).

\section{Conclusion}

Summing up the above-mentioned views we may come to conclusion that as it is in the way literary languages, in the terminological systems belonging to different languages intended for special purposes, in ICT terminology as well, various semantic events-policemy, synonymity, omonymity and other phenomena show themselves.

\section{References}

Akhamona, O. S. (1966). Dictionary of linguistic terminology. Soviet Encyclopedia.

Collins, V. H. (1970). The choice of words. Longman: Group Limited.

Danilenko, V. P. (1977). Russian terminology. Experience of linguistic description. Nauka.

Golovin, B. N., \& Kobrin, R. U. (1987). Linguistic fundamentals about terms. Visshaya Shkola. 
Juravlev, A. P. (1987). Dialogue with a computer. Molodaya gvardiya.

Kandelaki, T. Sh. (1977). Semantics and motivated terms. Nauka.

Malinovski, B. (1998). The Translation of Intranslatable Words. In A. Nye (Ed.), Phylosophy of Language: the Big Questions. Blackwell Publishers.

Marusenko, M. A. (1981). About the basic concepts of terminology—term scientific and technological. Scientific and technical information, 2(8).

Matezius, V. (2003). Selected works on linguistics. URSS.

Pershikov, V. I., \& Savinkov, V. M. (1991). Glossary of Computer Science. Finance and Statistics.

Sadigova, S. (2002). Theoretical problems of terminology of Azerbaijani. Baku.

Salahova, S. (1990). Some issues of formation of Azerbaijani technological terms. Terminology issues. Bak1.

Shabanov, R. M. (1998). Synonymic problems in terminology of Azerbaijani. NDA, Baku

Toropchov, I. S. (1964). Lexical motivation (based on Modern Russian literary language). Scientific record. Oryol, OGPU.

Yarcheva, V. N. (1990). Dictionary of linguistic encyclopedia. Soviet Encyclopedia.

\section{Copyrights}

Copyright for this article is retained by the author(s), with first publication rights granted to the journal.

This is an open-access article distributed under the terms and conditions of the Creative Commons Attribution license (http://creativecommons.org/licenses/by/3.0/). 